\title{
A SIMULATION MODEL FOR LONG-TERM ANALYSIS OF THE ELECTRICITY MARKET
}

\author{
Ilhan Or \\ Department of Industrial Engineering \\ Bogazici University \\ 80815, Bebek/Istanbul \\ E-mail: or@boun.edu.tr
}

\author{
Guzay Pasaoglu Kilanc \\ Department of Industrial Engineering \\ Istanbul Kultur University \\ 34156,Bakirkoy/Istanbul \\ E-mail: g.pasaoglu@iku.edu.tr
}

\section{KEYWORDS}

Electricity Market, System Dynamic, Simulation.

\begin{abstract}
After the liberalization of the electricity generation industry, capacity expansion decisions are made by multiple selforiented power companies. Unlike the regulated environment, decision-making of market participants is now guided by price signal feedbacks and by an imperfect foresight of the future market conditions that they will face. In such an environment, decision makers need to understand long-term dynamics of the supply and demand side of the power market. To visualize the competitive electricity power market dynamics, a simulation model based on system dynamic philosophy is developed in this study. The developed model includes the demand module, the capacity expansion module, the power generation sector, an accounting and financial module, various competitors and a bidding mechanism (power pooling system). By means of such a decision tool, companies and regulators have a better opportunity to understand possible consequences of different decisions that they may make under different policies and market conditions. The main part of the paper is devoted to a detailed presentation of the model. At the end, some findings of the preliminary scenario analysis are discussed.
\end{abstract}

\section{INTRODUCTION}

Before the liberalization of the electricity industry, investments in power plants used to be the result of an optimized centralized capacity expansion planning at national or regional level. The aim of this planning was to determine the right level of generating capacity, the optimal mix of generating technologies and the timing of the investments and retirements of capacity to ensure that future demand in a certain region would be served at minimum cost with an adequate level of reliability $(\mathrm{Ku}, 1995)$. In such an environment, the future demand and future fuel prices are the only significant sources of uncertainity. Additionally, producers are not price takers, i.e.,they have opportunity to dermine market price.

After liberalization of the electricity industry, electricity is no longer supplied by one monopolistic supplier. In the resulting competitive environment, combined forces of supply and demand conditions, rather than the historic costs of the underlying assets will determine electricity prices. Besides, expected electricity price is a major factor which triggers or postpones the investment decisions of power companies. On the other hand, although short-term demand elasticity is too low, longterm demand elasticity is between -0.5 and -1.5 . (Stoft, 2000). Considering these arguments, we can say that investment decisions mainly depend on cash flow expectations of the investor and on the dynamics of demand and supply in the power market, while policies, constraints and availabilities regarding, incentives, taxes, transmission needs, primary energy reserves, real time pricing issues, seasonal effects, current plant portfolios of the producers, greatly influence these primary factors.

In such an environment, the decision makers- individual power companies or a public regulating authority, try to answer the following questions; How much new capacity should a generating company build in order to meet growing demand and to increase or preserve its share in the market? At what price should generators price their products in the market, in order to balance market share, solvency, short term profitability and long term expectations? Whether withholding (deliberately reducing available electricity with the aim of increasing prices) is a profitable strategy or not? Which types of plants will be more attractive in decentralized, competitive environment? How will different competitors react against certain behavioral trends? Under which conditions renewable power plants will be attractive for the power companies? How can a regulator ensure that competitive prices prevail in the market, whilst sufficient incentives for capacity expansions and new entries are maintained? etc.

To answer questions such as the ones forwarded above, decision makers need to understand long-term dynamics of the supply and demand side of the power market, as investment decision depends on it. Since, system dynamics focuses on learning and understanding the system (instead of predicting the future), to visualize the competitive electricity power market dynamics, a simulation model based on system dynamic philosophy is developed in this study.

By means of such a tool, companies and regulators will have the opportunity to understand possible consequences of different decisions that they may make under different 
policies and market conditions. Moreover, such a tool is a risk-free way for the managers to gain experience in a competitive environment which they are not familiar with. Besides, the model is suitable to test over 50,000 different scenarios which may be needed for decision makers to be considered in their strategic planning.

During the modelling process, various submodels have been developed and tested before they were integrated to form a complete system model. At each phase of the modelling, besides literature, expert opinions have been considered in determining the model structure, relationship between entities, parameters and equations used in the model. Currently, the study is at the scenario analysis phase, 64 scenarios have already been configured, run and and analysed.

After scenario analysis is completed, validation of the model will be accomplished. Then, by adding a userfriendly interface to the model, the decision tool will be completed.

The main part of the paper will be devoted to a detailed presentation of the model. At the end, some findings of the preliminary scenario analysis are introduced.

\section{LITERATURE REVIEW}

System dynamic methodology has been used for analysis of the privatization and deregulation processes of electricity markets all over the world (Bunn and Larsen, 1992; Bunn, Larsen and Vlakos, 1993; Bunn et al, 1997; Vlakos, 1998) used system dynamic methodology in their studies which focus on deregulated electricity market. Research on investment cycles-boom and busts- observed in the United States' electricity market is presented in (Ford 1999; Ford 2000). Columbian energy market has also been analyzed in (Dyner and Larsen1997)

\section{FEATURES OF THE DEVELOPED MODEL}

\section{General characteristic}

In this study, the post-deregulation Turkish Electricity Market is modeled based on system dynamic approach, through STELLA 7.01 R. The model simulates the development of the liberalized power market for a 20 years period, on a monthly basis. Besides, every 5 years it is possible to pause the current simulation run (so called "a game") so that the player can update various parameters if he or she so chooses.

The situation that players are faced with, at the start of the simulation, is a market that has recently been opened to competition.

Constraints on transmission capacity between the various regions are not considered in the model.

The most important factors, which are considered in the model, are briefly presented in the remaining of the paper.

\section{Players in the Model}

There are five players in the model which are of three types. These are,

i) the incumbent (holding a major share of the current market),

ii)three Independent Power Producers (IPP) who are generally smaller in size but are more focused and agile (regarding generator inventories, decision making and cash flows) and tend to stand and succeed in the market by competing with the incumbent, and

iii) one New Entrant (NE) which may enter the market according to the market conditions.

The model-user selects his/her role at the beginning of the game:

1. Either he assumes one of the above stated player types (active player), and the rest of the players (passive players) are driven by the computer, or

2. He inputs all the parameters describing the market behavior; then, all the players are driven by the computer (passive players).

In the model, default rules/settings are defined for each player.

\section{Characteristic of the Power Companies}

The Incumbent exists in the market at the beginning of the model. As previously stated, it holds a major share in the market. The Incumbent has the highest capacity and highest capital among all players. The Incumbent's main business objective is to maintain his current market share and profitability.

In the model there are 3 Independent Power Producer groups. These power generators also exist in the market at the beginning of the model. In comparison to the market share of the Incumbent, these players have lower market shares. Their main business objective is to maintain their current market share and profitability. They have the chance to takeover divested plants of the incumbent when (because of anti-monopolistic considerations) the regulator requires the Incumbent to sell some of its power plants.

New Entrant (NE) does not exist in the market at the beginning of the model. He has lower cash than the other players. He has low (debt financing) credibility because of his low book value (fixed assets). He can enter the market in 2 conditions; after his/her new power plants under construction are completed or by taking over the divested plants (by the regulator) of the incumbent.

There are some advantages of taking over divested plants. Since divested plants are already built and delivering electricity, there is no need to wait for their construction. Additionally, as the divested plant is an already existing one, its book value is lower than that of new plant investment; so, it is cheaper to take over capacity rather than constructing new capacity. 


\section{The Regulator}

The Regulator (a passive player in the model), oversees the market and aims to facilitate the creation of competitive conditions and to ensure fair prices for the consumers. Given that the Incumbent has a large market share initially, the Regulator is particularly aware of the potential abuse of this power (and possible monopolistic tendencies). The regulator orders divestment if he deems it necessary. This means that the regulator requires the Incumbent to sell some of its plants, if the market share of the Incumbent is greater than or equal to a predetermined level. The generating capacity up for sale is offered to each player on an equal opportunity basis. Producers; (the NE and the IPPs) may buy the offered part of the Incumbent's plants as much as their financial power, (cash and credit) let them. Additionally, in case of divestment, distribution companies offer debt loans with comparatively lower interest rates to Independent Power Producers and the New Entrant. This is mainly due to anti-monopolistic considerations.

\section{Buyers}

Consumers and distribution companies are not explicitly modelled, but this part is reflected to the model within the framework of a detailed demand profile.

\section{Demand}

Transmission losses and reserve margin requirements are assumed to be included in the demand profile. Consequently, there is a single electricity price for the overall region, so that price differences within the region due to transmission congestion are not taken into account.

At the beginning of the simulation, peak demand, longterm demand elasticity and annual growth rate of demand are entered to the model. Additionally, if the player wants, he/she can change these values every five year. Default annual growth rate of electricity demand is 7\%. As previously mentioned, the simulation model uses monthly-based periods. In the model, each day of a month is assumed similar in terms of demand characteristic, with each day being divided into 9 time intervals and each interval's demand being a predetermined percentage of peak demand (these percentages are determined based on hourly load curves data obtained from TEIAS - the Turkish Electricity Transmission Company).

During a simulation run, the monthly peak demand values are updated with respect to annual peak demand growth rates. Then, based on the hourly load curves, and peak demand projections, demand projections for each month and each time interval are individually determined.
In the model, long-term demand elasticity is given consideration. When running the model, at the beginning of each year, last 4 year's average electricity price is calculated as a reference market price and then compared with the average price of the last year. If the last year's market price is higher than the calculated reference market price, demand is further adjusted due to demand elasticity. (demand elasticity is defined as the percentage change in demand that occurs in response to a percentage change in price).

In addition to the above attributes and characteristics considered in the demand module, different load curve patterns are also offered to the model user to use in his scenario analysis.

\section{Power Plants}

There are several plant types in Turkey categorized according to their primary energy resources. These resources play key roles on cost and availability features. In the model, each player has the opportunity to build/own generating plants out of 8 different plant types as long as he/she has the necessary funding (either as capital and/or financing) These 8 plants are; geothermal, wind, imported hard coal, diesel oil, lignite, natural gas, small hydropower plants, large hydropower plants. However, due to some restrictions of Stella, the overall available capacity (in MW) of each plant type (rather than the capacity of each individual plant) is considered for each player (for building, owning, operating, depreciating and disposing).

Deciding on the plant type to be built is a strategic decision for individual players. Decision makers have to evaluate these power plants based on their marginal cost, capacity and availability factor, $\mathrm{CO}_{2}$ emission (if $\mathrm{CO}_{2}$ tax is applicable), variable cost, fixed cost, economic plant life and capacity cost characteristics.

The model is equipped with monthly availability data for wind and hydropower plants. Besides, based on historical data of the last 30 years, the precipitation profile of Turkey is determined as $65 \%$ moderately rainy, $20 \%$ dry and $15 \%$ very rainy. To reflect this flexibility to the model, during a simulation run, at the beginning of each year, the amount of annual precipitation is randomly generated considering the seasonality effect and then the availability for hydropower plants is determined based on the generated precipitation figures.

Besides, it is assumed that as power plants get older, their availability also decreases.

\section{Power Pool}

Since, the model is developed over monthly-based periods, the bidding process is also based on monthly periods and an electricity pooling system is implemented. As mentioned, each day of a month is 
assumed similar in terms of demand characteristic. However, the electricity demand of each month is different from one other. In the model, for each succeeding month, the generators declare their production capacities and submit bids to the regulator. Each bid specifies a certain 30 minute interval for a certain day and offers a certain amount of power (in MWh) under a certain unit price. To satisfy the next month's demand, the Regulator determines the amount of the electricity to be bought from each generator and the system marginal price for each time interval of the next month. During this phase, the players are contracted by the regulator (i.e. their bids accepted) in ascending order of price. The most expensive unit bought establishes the system marginal price (SMP) which all contracts receive during that month for that time interval. In the model, if the generators offer the same price, first priority is given to the NE then to IPPs finally to the Incumbent, to encourage new entry.

In the liberalized electricity market, the Regulator offers, an additional price mark-up, which is designed to provide an incentive for future investment of additional generation capacity. This mark-up is based on VOLL (value of loss load) and LOLP (Loss of Load Probability). (Bunn et. al 1997). The regulator assesses and sets the value for loss of load (VOLL). In our model, mentioned price mark-up is also offered to the generators. LOLP is a function of excess capacity. Excess Capacity in turn is calculated by the Equation 1.

ExcessCapa city $=\frac{\text { TotalInsta lledCapaci ty }- \text { PeakDemand }}{\text { PeakDemand }}$

In the simulation, the default LOLP function is made available to the players and the game setter has the opportunity to change this function at the beginning of the game.

\section{Incentives}

If the market share of the incumbent is more than a predetermined level, low cost loans (in other words, discounted loans) are made available for the IPPs and the NE as an additional incentive. Capacity payments based on VOLL and LOLP can be considered as another indirect incentive.

In the EU countries it is aimed that by $2010,22 \%$ of the energy generated will be produced by renewable resources. In line with this EU aim, various renewable energy power plants (REPP) incentives are implemented in the simulation model: These are; government subsidy loans and extra tax exemptions.

Besides the investment incentive offered for the REPP, there is also an additional $\mathrm{CO}_{2}$ tax for thermal power plants (natural gas, hard coal, diesel oil and lignite type of power plants).
The Incentive for REPP and the exercise of the $\mathrm{CO}_{2}$ tax are left optional in the model (i.e. to be activated by the game setter).

\section{Profit Margin}

Expected Profit margins of all player types are input to the model by the players at the beginning of each game and then can be updated every 5 years.

Due to the mechanics of system dynamics and Stella Software, profit margins are not calculated within the system; in other words, price optimization is out of the scope of this model.

\section{Taxation}

Tax is another issue given consideration in the model. If not set otherwise at the beginning of the game, the tax rate is fixed to $30 \%$ by default. Tax is calculated for earnings after fixed costs, variable costs, interest costs and depreciation costs. (The method deployed for depreciation is linear for a period of 20 years.)

According to the present relevant legislation in Turkey, $40 \%$ of fixed asset investments may be deducted from the pre-tax profit (which means that no tax is incurred until cumulative pre-tax profit gets more than $40 \%$ of the new investment). The implementation of the mentioned tax exemption is left optional in the model (i.e. to be activated by the game setter).

\section{Behavior of Power Companies in the Market}

In the model, it is assumed that power companies may want to overtake risk at 3 different levels of "aggression". These levels are described as; Aggressive, Neutral and Conservative. We assumed that as companies gets more aggressive, their expected internal rate of return for a new investment and their profit margins decreases, accordingly, their willingness to build new power plants (at less expected profit and therefore at increased risk) increases.

\section{Long-term Contracts}

Long-term contracts can optionally be included in the model. If no long-term contracts are included, this means pure pooling mechanism prevails the model (No long-term contracts are considered in the default model). The game-setter may change this option on the model interface and include long-term contracts in the system. In this case, the active producer is asked to define the portion of his/hers capacity that he/she wishes to be allocated to long-term contracts $(\% 15, \% 10, \% 5$, $\% 0$ ).

A reference value for the long term contract price is determined based on the average price of the last 5 years. Long-term contract price for the first 5 years, on 
the other hand, may be input by the player at the beginning of the game (the default value of which is assumed to be $80 \$ / \mathrm{MWh}$ ).

The portion of passive players' capacities that are to be allocated to long-term contracts vary depending on their aggression level. Similarly, contract prices of the passive players also depend on their aggression level. Aggressive players are assumed to take more risks and as such be willing to have less long-term contracts, compared to more conservative players.

As the number of long-term contracts in the market increases, the contract price of the next contract is assumed to be more competitive (i.e. lower). If long term contract option is activated, long term contract price changes for passive players, are illustrated in Table 1.

Table 1: Relationship between long-term contract price, aggressiveness of the player and supply amount of the passive players that allocated to the long term contract.

\begin{tabular}{|c|c|c|}
\hline Behavior & $\begin{array}{c}\text { \% of } \\
\text { player's } \\
\text { capacity } \\
\text { allocated } \\
\text { with long } \\
\text { term } \\
\text { contracts }\end{array}$ & $\begin{array}{c}\text { Contract Price } \\
(\$ / \mathrm{MWh})\end{array}$ \\
\hline Aggressive & 5 & $\begin{array}{c}(1-0.05) \times \text { last } 5 \\
\text { years market price }\end{array}$ \\
\hline Neutral & 10 & $\begin{array}{c}(1-0.10) \times \text { last } 5 \\
\text { years market price }\end{array}$ \\
\hline Conservative & 15 & $\begin{array}{c}(1-0.15) \times \text { last } 5 \\
\text { years market price }\end{array}$ \\
\hline
\end{tabular}

\section{Reserve \& Capacity Addition Limit}

Employment of electricity generation alternatives are limited with resource availability and reserves. Reserves can be input by the player at the beginning of the game and/or updated every 5 years.

Besides the reserve limits, the game setter may decide whether or not to have an annual capacity addition limit (additional capacity per technology per year) in the game. If it is decided to have such limits, the values given by TEIAS are used (i.e. 1500 MW new hydropower, $500 \mathrm{MW}$ new small hydropower, $125 \mathrm{MW}$ new wind plants are allowed to be invested in annually).

Reserve and capacity addition limits are distributed among the players on an equal basis.

Reserve, throughout this paper, is defined as follows:
- For hydropower, wind, geothermal and lignite plants: actual physical reserve of the resource of the country.

- For natural gas and diesel oil plants: 4 times the existing purchase contracts at the beginning of the simulation run.

\section{Withholding}

"Withholding" is defined as a generator deliberately reducing the available electricity in order to increase the market price. In the developed model, the game-setter may choose to have such a withholding option in the game or not (in the default setting, it is not included).

If witholding prevails in the game and if the incumbent's capacity exceeds $40 \%$ of total productive capacity in the market, the incumbent witholds $25 \%$ of his productive capacity excluding long-term contract requirements.

\section{Capital Budgeting}

Since, power plant investments are highly capital intensive, the required capital is generated as a combination of debt and equity. Default debt-equity ratio in capital budgeting of new investments is 3 (based on the suggestions of some professionals in the market) but can be set to any other value at the beginning of the game or during the simulation run (at the 5 year pauses).

The credibility (debt financing) of a company, on the other hand, is defined as a function of the book value, last period's profitability, past years' profitability and current credit burden of that company.

\section{Investment Decisions of Active Players}

An active player can define his/her investment strategy using the game interface by setting the annual constant capacity expansion rate of new investment and its composition in terms of power plant types.

The model provides decision support to the active player with many tables and figures in the Stella environment, which comprehensively reflect the behavior and conditions of the market. As the consequences of the decision is totally up to the active player himself, no feasibility check, in terms of profitability, is applied on such decisions. The decision of the active player is, however, checked regarding the affordability of the investment in terms of it potential cash flow requirements. If the investment can not be afforded completely, it may be partially undertaken (as much as it can be afforded by the player).

\section{Investment Decisions of Passive Players}

At the beginning of the game, the forecast period is asked to the model-user, which is then used in 
estimating the near future demand-supply gap in the market. The period may be between 0-60 months, and once fixed, it is applied for all the passive players. Demand-supply gap within the next forecast period is determined based on the future peak demand, existing capacity, potential retirements and capacity under construction. It is assumed that, at the beginning of each year, all passive players evaluate current situation in the market and their relative position within the forecast period. If there is a demand-supply gap within the next forecast period, and the sum of the variable cost of a power plant and player's profit margin is greater than last year's average pool price, then feasibility of constructing the related power plant is determined based on the NPV (net present value) of the future cash flows (which depend on expected market price).

As previously mentioned, system marginal price is determined by the marginal costs of power plants in the market. Therefore, the composition of power plant portfolio of the market directly influences the market price. This effect is reflected to the expected pool price by means of weighted average of the marginal costs of the current power plant portfolio. As a consequence, the expected market price is determined based on simple trend extrapolation of the pool price within the forecast period and weighted average of the marginal cost of the current power plant portfolio

The discount rate used in the NPV analysis for different types of power plants, is the weighted-average cost of capital. The time span used in the NPV, is the economic life of the plant type under consideration.

Weighed average cost of capital (WACC) is calculated as displayed in equation 2 ;

$W A C C=\left[\frac{\text { debt }}{\text { investment }} \times(1-\right.$ taxrate $\left.) \times r_{\text {debt }}\right]+\frac{\text { equity }}{\text { investment }} \times r_{\text {equity }}$

The rate of return expectation of passive players varies according to the player type and the designated aggression level (the amount of risk the players want to overtake in the market decreases as their aggression level decreases). As mentioned, it is assumed in the model that aggressive players expect lower rates of return than less aggressive players. On the other hand, a New Entrant expects the highest internal rate of return, whereas the Incumbent expects the lowest one. Because of this reason, by differentiating $r_{e}$ (cost of equity), different discount rates are used in the NPV analysis, for different players.

The default values of cost of equity and debt are as follows:

Cost of equity $\left(r_{e}\right)$ is $11.5 \%$; cost of debt $\left(r_{d}\right)$ is $7 \%$.

Assumptions of NPV analysis:

- In the NPV analysis, after-tax earnings are used as monthly cash inflows.
- Debt-financing loans are paid back as monthly installments and (if not otherwise set at the beginning of the game) payment period of all loans is fixed as 10 years by default.

- Equity financed portion of every investment flows out as constant installments during whole construction period.

- For any time interval, the ratio of the average load to the peak load is 0.76 . i.e. the expected amount of electricity that a passive player can sell is $76 \%$ of his productive capacity. This is simply because of the fact that a passive player determines his investment amount considering expected supplydemand gap which on the other hand depends on forecasted peak demand.

- $\quad$ The NPV calculation is based on 1 MW capacity of the plant type under consideration.

- If the NPV of an investment option is negative, that investment does not launch.

If the NPV of cash flows is positive, the amount of the investment is determined by the size of the supplydemand gap, the aggression level of the players involved and reserve availability of each primary energy alternative.

The passive players are assumed not to invest on a single type of power plant (the one having the maximum NPV among all power plant types), but prefer diversity. This assumption is based on several reasons;

1) In the liberalized electricity market, future revenue streams are no longer guarantied through regulated tariffs, since generators are rewarded an uncertain price for the energy sold. As previously mentioned, electricity market price is sensitive to the composition of plant portfolio of all power generators. Furthermore, the ability of generators to sell energy depends now upon their dynamic (i.e. for each interval) cost competitiveness relative to their competitors.

2) As imported hard coal, natural gas and diesel oil, are mainly supplied by foreign countries, it is not easy to attain sustainable availability and price stability for these primary energy resources. In case of a crisis, there is high risk for producers, dependent on these resources, of not being able to sell their production under price pressure of their competitors (which may be independent of that fuel types). The availability of hydropower and wind plants, on the other hand, is highly dependant on seasonal variations. In other words, irrespective of plant type, either renewable or thermal, investors face different levels of risk perceptions and realizations.

3) In addition to the above stated arguments, if the investors concentrate only on one type of power 
plant (i.e. natural gas, hard coal etc.), fuel cost of that power plant may exhibit additional increases due to the escalating demand of the related fuel.

Accordingly, the capacity expansions of passive players are distributed among different power plant types, (which have positive NPV), according to the ratio given in Equation 3.

$$
\frac{\frac{N P V_{i}}{\text { Investment Cost }{ }_{i}}}{\sum_{k=1}^{k} \frac{N P V_{i}}{\text { Investment Cost }{ }_{i}}}
$$

Where $\mathrm{k}$ is the number of power plant types with positive NPV.

The nominator in Equation 3 is the investment rate of return for each type of power plant, whose internal rate of return is more than or equal to WACC.

\section{First Preliminary Scenario Set}

The model has a flexible structure for parametric studies where parameters affecting the market can be changed and the results of selected strategies/policies (set of parameters) can be analyzed. The total number of scenarios that can be simulated is more than 50.000 because of combinatorial interaction between parameters and strategies. Evaluating all these scenarios would require vast amount of computation and analysis time. Therefore, in the preliminary scenario analysis, only those scenarios, that are designated as "more critical" are considered. In order to obtain these sets, policies are grouped under 2 categories. The first group consists of producer related issues, whereas the second group includes environmental and regulatory issues. The attributes considered under these groups are given in Table 2.

In the first test bed the model is run considering the following cases:

- All players being aggressive or all players being conservative;

- Incumbent exercising withhold or not ;

- Long term contracts being available or not;

- Seasonal effects on the availability of wind and hydropower power plants implemented or not;

- Players investing in only the 6 most preferred plant types (which are natural gas, small hydropower, large hydropower, wind, imported hard coal and lignite) vs. players investing in all available plant types.

In the second test bed, the model is run considering the following cases:

- Demand elasticity being active or not;

- Annual capacity addition limits existing or not;

- $\quad$ VOLL being 2000 \$/MWh versus VOLL being 3000 \$/MWh;
If the distribution percentages calculated above cannot be applied because of reserve and/or capacity addition limits of some plant types, the unmet investment demand is distributed among the plant types with sufficient reserves and appropriate capacity addition status, through the ratio given in Equation 4.

$$
\begin{aligned}
& \frac{N P V_{i}}{\text { Investment Cost }} \\
& \overline{\sum_{i=1}^{n} \frac{N P V_{i}}{\text { Investment } \text { Cost }_{i}}}
\end{aligned}
$$

where $\mathrm{n}$ is number of plant types with positive NPV and sufficient reserve.

To sum up, a graphical illustration of main factors influencing investment decision of the passive players is given in Figure 1.

- $\mathrm{CO}_{2}$ tax existing or not;

- Governmental support for renewable investment being available or not.

Table 2: Parameters Analyzed in 64 Scenarios

\begin{tabular}{|l|c|l|c|}
\hline \multicolumn{2}{|c|}{$\mathbf{1}^{\text {st }}$ Test Bed } & \multicolumn{2}{c|}{$\mathbf{2}^{\text {nd }}$ Test Bed } \\
\hline $\begin{array}{l}\text { Issues } \\
\text { Issucer Related }\end{array}$ & Lvl & $\begin{array}{l}\text { Environmental } \\
\text { and Regulatory } \\
\text { Issues }\end{array}$ & Lvl \\
\hline Withholding & 2 & Demand Elasticity & 2 \\
\hline $\begin{array}{l}\text { Long term } \\
\text { Contracts }\end{array}$ & 2 & $\begin{array}{l}\text { Annual Capacity } \\
\text { Addition Limit }\end{array}$ & 2 \\
\hline $\begin{array}{l}\text { Seasonal Effects on } \\
\text { Availability }\end{array}$ & 2 & CO $_{2}$ Tax & 2 \\
\hline $\begin{array}{l}\text { Power Plant Types } \\
\text { Considered } \\
\text { (first 6 or all) }\end{array}$ & 2 & $\begin{array}{l}\text { Governmental } \\
\text { Support for } \\
\text { Renewable }\end{array}$ & 2 \\
\hline Total & $\mathbf{3 2}$ & Total \\
\hline $\begin{array}{l}\text { Note. All of the producers are driven by the computer. } \\
\text { Lvl numbers denote the number of values of that } \\
\text { parameter used in the scenario analysis. }\end{array}$ \\
\hline
\end{tabular}

As described before, there are five different producers (players) in the model with three optional behavior types (aggressive, neutral, passive), which means 243 $\left(3^{5}\right)$ different cases. Considering the four remaining parameters included in the first test bed together with these 243 combinations will result in 2916 different scenarios. As it would require a large amount of time to analyze all these scenarios, instead of considering all combinations, it was assumed that all five players are either aggressive (all together) or conservative (all together). The resulting test bed includes only 32 scenarios with this assumption.

Similarly, in the second test bed only two alternative values were considered for each of the five parameters, 
which ended up with 32 scenarios. In the present study, these 64 scenarios were evaluated for 32 different indicators describing the market (such as market share of the players, SMP, pool price, remaining primary energy reserves, revenue of the players, peak demand, total installed capacity).

\section{RESULTS OF THE PRELIMINARY SCENARIO ANALYSIS}

Only a limited number of results are shown here, as the main focus of this paper has been on the presentation and discussion of the developed model.

It should be noted that, by changing the game settings it is possible to analyze the effects of various parameters/issues (ranging from natural effects like precipitation level to decisions of the regulatory authority such as incentives, tax exemptions, quotas on annual capacity addition of some power plant types) on the behavior of the electricity market,

Results of three scenarios (out of 64) are discussed in (Table 3 and Table 4) as an example. In each table, 2 different scenarios are compared with each other, similar properties of both scenarios are explained in merged cells. If different behaviors are observed in the compared scenarios, these are explained in separate columns.

In scenarios discussed in Table 3 and Table 4, the following parameter settings were assumed:

- $\quad$ Players are conservative;

- $\quad$ Long term demand elasticity is $-0,5$;

- There are, no withholdings, no $\mathrm{CO}_{2}$ tax, no long term contracts;

- Annual precipitation level is fixed for each year (no random effects are considered).

In addition to the above parameters, whereas renewable support (government subsidizes $20 \%$ of renewable energy based generation investments) exists in the first scenario and second scenario, it does not exist in the third scenario.

The only difference between the first scenario and second scenario is the existence of annual capacity addition limit, which does not exist in the first scenario, and does in the second. Annual capacity addition limit also does not exist in the third scenario.

The only difference between the first scenario and the third scenario is the existence of renewable support, which exists in the first scenario, and does not in the third.

Market behaviors associated with the first and second scenarios differs from one other especially after year 4 . The dynamics of the market is displayed in Table 3. Comprehensive analysis of the 64 scenarios yielded the following major findings on the dynamics of electricity market.

1. In case of inelastic demand, the increasing demand is preferred to be met by plant types having lower marginal and investment costs. As the reserve of these plant types are used up in time, other, more expensive investment options are undertaken and the pool price displays sharper increases in the face of rapidly increasing demand.

2. If the demand is price elastic, the increase in demand is much slower and reserves for all plant types remain available throughout the planning horizon. Consequently, there is no need in the market to invest heavily in hardcoal and diesel plants and pool price increases are softer.

3. In the 64 scenarios considered, no wind power plants are undertaken (probably because of their high marginal and investment costs). Even if there is $20 \%$ governmental support, investing in wind power plants does not become desirable.

4. If there is no capacity addition limit, indifferent to the other game settings, power companies prefer to invest in small hydropower plants before $60^{\text {th }}$ month.

5. The major effect of governmental support for renewable plants is changes in the market plant portfolio composition in favor of large hydropower and geothermal plants and consequently a decrease in system marginal price.

As the construction time for hydropower plants is comparatively longer (5.5 years on average) than other plant types, the growth rate for installed capacity remains lower than the demand growth rate during some time periods within the simulation run, which in turn causes prices to fluctuate and demand (if price elasticity is non-zero) to decrease.

Besides, governmental support for renewable plants acts as an inducement for competitors to enter the market with new power plants which in turn reduces the market share of the Incumbent.

6. As the major part of already existing power plants in the market is thermal power plants, imposing $\mathrm{CO}_{2}$ tax causes the pool price to increase.

7. In case of demand elasticity, due to $\mathrm{CO}_{2}$ tax (and the resulting price increase) demand/demand growth rate and new investment amount decreases.

8. In case of demand inelasticity, imposing $\mathrm{CO}_{2}$ tax causes a shift in new investments from 
thermal plants to renewable plants within the limits of relevant reserves.

9. Withholding raises the market price and this causes the competitors to enter the market with new power plants. As a result, due to increasing installed capacity i.e. increasing excess capacity, Incumbent's market share and market price decreases.

Besides, in case of demand elasticity, the effect of withholding (and the resulting price increase) is decrease in the demand/demand growth rate. As a result, there exists too much installed capacity. Because of this reason market price decreases.

\section{CONCLUSION}

In this paper, an extensive model for long term analysis of deregulated power market is presented. The results obtained from preliminary scenario analysis reveal that the model is able to capture parts of the long-term dynamics which occur on both the supply and demand side of the power market. Although the default parameters have been obtained from Turkish Electricity Market, the model can be used in general by changing the parameters via the user-interface. By means of such tool, power companies and the regulators have a better opprtunity to understand possible consequences of different decisions that they may make under different policies and market conditions. As a future study, a stochastic price description may be done to take into account the volatility in the expected price.

\section{REFERENCES}

Bunn, D. and E.R.Larsen, 1992, "Sensitivity of Reserve Margin to Factors Influencing Investment Behaviour in the Electricity Market of England \&Wales", Energy Policy, Vol. 29, pp.420-429.

Bunn., E.R. Larsen and K. Vlahos, 1993, "Complementary Modeling Approaches for Analyzing Several Effects of Privatization on Electricity Investment", Journal of Operational Research, Vol. 44, No. 10, pp.957-971.

Bunn, D. and I. Dyner and E. Larsen, 1997, "Modelling Latent Power Across Gas and Electricity Market", System Dynamics Review, Vol. 13, No. 1, pp.271-288

Dyner, I. and E. Larsen, 1997, "A System Simulation Platform to Support Energy Policy in Columbia", System Modeling for Energy Policy, pp 259-271, John Wiley and Sons, Chichester.

Ford, A., 1999, "Cycles in Competitive Electricity Markets: A Simulation Study of the Western United States", Energy Policy, Vol. 27, pp. 637-658.

Ford, A., Simulating Patterns of Power Plant Construction with the CEC Model Summary Report to California Energy Commission, California, USA.
$\mathrm{Ku}$, A., 1995. Modelling Uncertainty in Electric Capacity Planning, Ph. D. Thesis, London Business School.Stoft, S., 2002. Power System Economics., pp. 43, Wiley, USA

ILHAN OR was born in Istanbul, in 1951. He obtained his B.S., M.S. and Ph.D. degrees from the Industrial Engineering Department at Northwestern University (Evanston, U.S.A.). He has been a faculty member at Boğaziçi University Industrial Engineering Department since 1976; he has also held various administrative positions at Boğaziçi University, including the Directorship of the Graduate School of Science and Engineering (2005 - ), Senatorship at the University's Senate (2005 - ) and Chairmanship of the Industrial Engineering Department (between 1994-98, and since 2003). In 1983-84 period, he worked at Syracuse University (New York - U.S.A.) and at the University of Maryland (Maryland - U.S.A.) as a visiting professor. He has received his Associate Professor and Professor titles in 1984 and 1991 respectively.

Major fields of research and teaching interest of Ilhan Or are linear programming, production and maintenance planning problems, risk analysis and management and operations research applications in energy planning. He has published many articles and made numerous presentations in international scientific journals and meetings, in these areas. He has also conducted continuing education and training seminars and worked as a consultant to industry in his fields of interest.

Ilhan Or served as an Associate Editor of Naval Research Logistics Journal in the 1993-2004 period. He has been a founding member of the Energy Economics Association of Turkey and of the Solid Waste Turkish National Committee; he is a member of the Turkish Statistics Society and the Operations Research Society of Turkey.

GUZAY PASAOGLU KILANC was born in Ankara, Turkey. She obtained her B.S. from the Industrial Engineering Department at Istanbul Technical University., M.S. from Industrial Engineering Department at Bogazici University. Currently, she is pursuing with her Ph.D. studies at Industrial Engineering Department, Bogazici University. She has been a lecturer at Istanbul Kultur University, Industrial Engineering Department since 1999.

Guzay Pasaoglu Kilanc's major fields of research are operations research and simulation, particularly in electricity market. 
Table 3: Comparison of the $1^{\text {st }}$ and $2^{\text {nd }}$ Scenario

\begin{tabular}{|c|c|}
\hline SCENARIO 1 & SCENARIO 2 \\
\hline \multicolumn{2}{|c|}{$\begin{array}{l}\text { Small hydropower plants are always attractive due to their lowest marginal cost (among } 8 \text { power plants } \\
\text { considered in this study) and lower investment cost in comparison to other renewable power plants. } \\
\text { As there is subsidy for renewable generation alternatives, large hydropower plants and geothermal power } \\
\text { plants become attractive for power companies. However, } 20 \% \text { government subsidy is not sufficient to foster } \\
\text { wind power plants to be constructed. }\end{array}$} \\
\hline $\begin{array}{l}\text { Hydropower plant investments are not limited by } \\
\text { annual capacity addition limit. As a result, major part } \\
\text { of new investments are in hydropower plants. }\end{array}$ & $\begin{array}{l}\text { Less hydropower plant investments are made due to } \\
\text { annual capacity addition limit. } \\
\text { New investments concentrate in other plant types in } \\
\text { order to keep demand-supply balance in the market. }\end{array}$ \\
\hline $\begin{array}{l}\text { As there are less NG plant investments, NG reserve } \\
\text { does not exhaust until the end of the simulation run. }\end{array}$ & $\begin{array}{l}\text { As there are many NG plant investments, NG reserve } \\
\text { exhausts after the } 200^{\text {th }} \text { month. }\end{array}$ \\
\hline $\begin{array}{l}\text { Since huge amount of hydropower plants enter the } \\
\text { market suddenly, system marginal price steeply } \\
\text { decreases down to circa } 33 \$ / \mathrm{MWh} \text { (owing to low } \\
\text { marginal cost of the hydroplants) at around } 180^{\mathrm{h}} \\
\text { month. As the hydropower reserve exhausts around } \\
180^{\text {th }} \text { month, extra NG power plants are constructed. } \\
\text { As a consequence SMP increases up to } 36 \$ / \mathrm{MWh} \\
\text { and remains almost constant until the end of the } \\
\text { simulation run. }\end{array}$ & $\begin{array}{l}\text { Since NG reserve exhausts after the } 200^{\text {th }} \text { month and } \\
\text { also, the expected pool price in the market is higher } \\
\text { than in Scenario } 1 \text { (due to higher SMP) investing in } \\
\text { lignite power plants becomes feasible and investments } \\
\text { launch at the } 228^{\text {th }} \text { month. }\end{array}$ \\
\hline
\end{tabular}

As the construction time for hydropower plants is comparatively longer than other plant types, the growth rate for installed capacity remains lower than the growth rate of the demand. As a consequence, average monthly pool price increases, which in turn causes demand growth rate to decrease.

At the end of the simulation run, peak demand is less than in Scenario 2.

As there is no capacity addition limit in the market, players' installed capacity increases rapidly due to new investments mainly in hydropower and geothermal plants.

As the variable cost of electricity generation in geothermal and hydropower plants is comparatively lower, the producers are able to offer lower bid prices to the power pool.

As there are less hydropower plants under construction, the installed capacity exhibits a comparatively continuous smooth increase trend (compared to step jumps for hydropower ones), parallel to demand increase trend due to shorter construction time. As a consequence average monthly pool prices fluctuate less than in Scenario 1 and peak demand at the end of the simulation run is higher than in Scenario 1.

Because of the capacity addition limit, less hydropower plants are installed which in turn means less total installed capacity in the market. As a result, incumbent's market share remains higher than in Scenario 1, though it exhibits a smoothly decreasing trend in time.

As a consequence of the above stated factors, market share of the incumbent decreases in time.

The tooth saw pattern observed in operating reserve and pool price graphs is owing to the different monthly load patterns prevailing in the electricity market. 
Table 4: Comparison of the $1^{\text {st }}$ and $3^{\text {rd }}$ Scenario

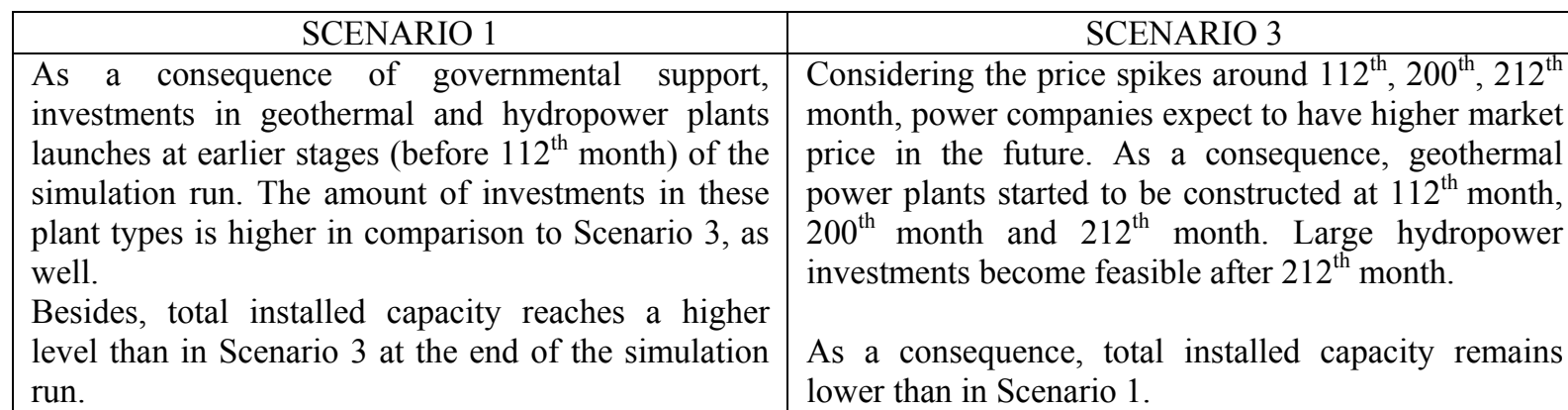

The proportion of renewable power plants within the total installed capacity is higher in Scenario 1 than in Scenario 3.

Average monthly SMP decreases faster and remains lower than the SMP in Scenario 3, because the variable cost of geothermal and large hydropower plants is lower than of other plant types.

As there is no governmental support for renewable plant types, geothermal and hydropower plants, which have lower variable costs but higher investment costs in comparison to other plant types, are constructed at later stages of the simulation run and have less proportion in the installed capacity compared to Scenario 1.

As a result, the SMP in Scenario 3 is higher than in Scenario 1.

Because of their high marginal and investment costs, diesel oil, imported hard coal and wind plants are not preferred at all. $20 \%$ government subsidy is not sufficient to foster wind power plants to be constructed.

Although its marginal cost is lower than NG Plants', lignite Plants have not been found feasible throughout the simulation run because of their high investment costs.

Small hydropower plants were widely preferred during the first 60 month of the simulation run, as they have the lowest marginal cost in comparison to other 7 alternatives. Moreover, their investment cost is less than large hydropower plants. As a consequence, small hydropower reserve is exhausted within the first 60 months.

In comparison to Scenario 3, more large hydropower plants and less NG plants are constructed because of governmental support for renewable plant investments.

As there are many NG plant investments, $\mathrm{NG}$ reserve exhausts after the $200^{\text {th }}$ month.

As there are less NG plant investments, NG reserve does not exhaust until the end of the simulation run.. After the small hydropower reserve has been exhausted in $48^{\text {th }}$ month, power producers concentrate on large hydropower plants. These plants became operational after $120^{\text {th }}$ month, which in turn enable all power producers to offer lower bid prices and higher capacity to the power pool. As a consequence, market share of the Incumbent decreases faster than in Scenario 3 after these new large hydropower start to generate.

The tooth saw pattern observed in operating reserve and pool price graphs is owing to the different monthly load patterns prevailing in the electricity market. 


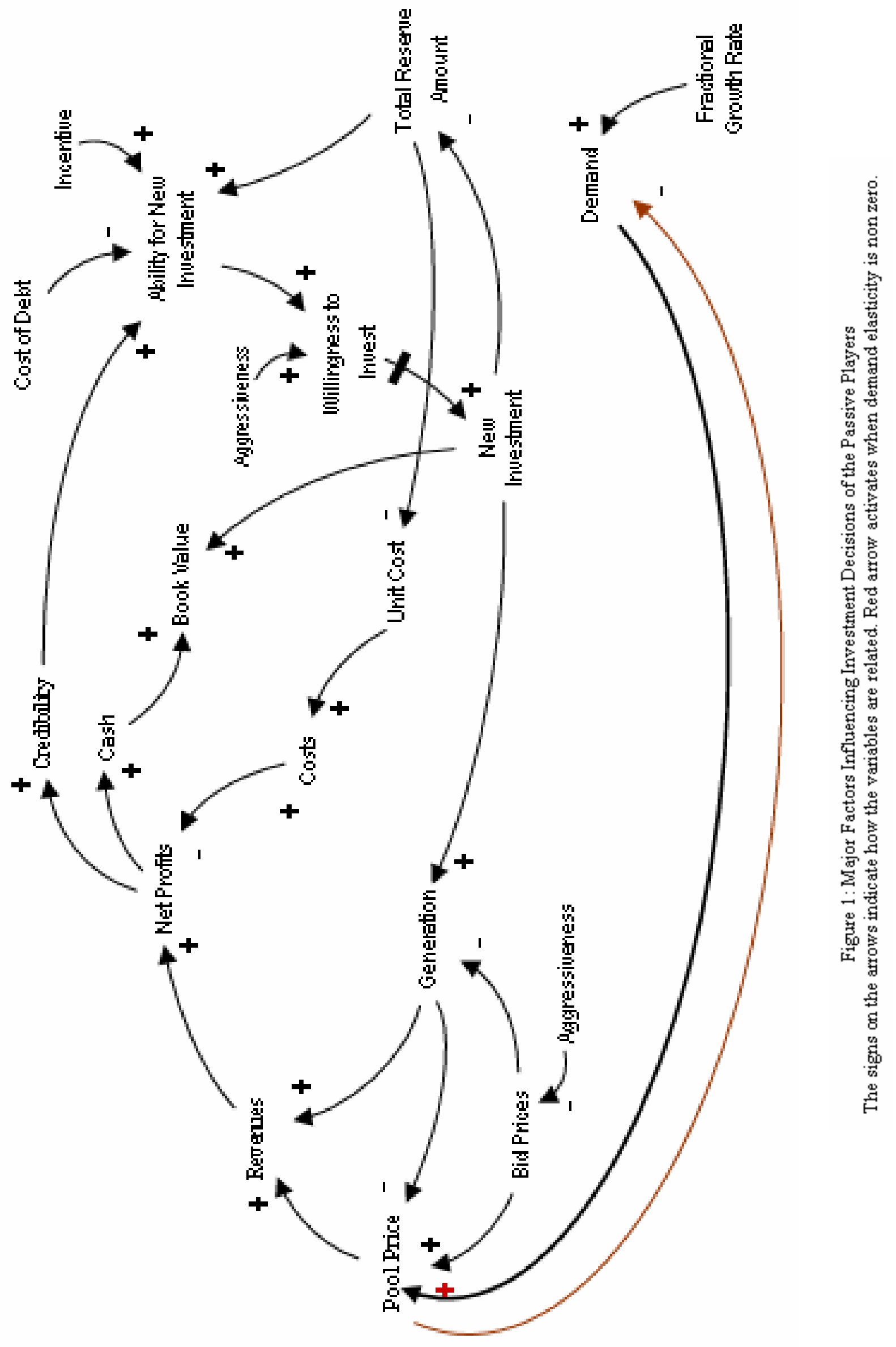

